\title{
POLA GERAKAN SOSIAL: RESISTENSI MASYARAKAT SAMIN DI ERA GLOBALISASI
}

\author{
Cahya Adhitya Pratama
}

\author{
Universitas Muhammadiyah Prof. Dr. HAMKA \\ pratamacahya344@gmail.com
}

$\underline{\text { Received : } 15 \text { July } 202 \text { |Reviewed: } 3 \text { August 2021 | Accepted: } 12 \text { August } 2021}$

\begin{abstract}
ABSTRAK
Dewasa ini kemajuan peradaban manusia mengalami kemajuan yang pesat. Perubahan sosial tidak lagi menjadi hal yang asing di era globalisasi. Salah satu masyarakat adat yaitu masyarakat samin yang memiliki karakteristik kuat dan pendirian untuk mempertahankan eksistensinya dalam kehidupan sosial. Masyarakat samin sejak dahulu telah melakukan gerakan sosial terhadap kebijakan-kebijakan pemerintah yang merusak kehidupan masyarakat samin. Artikel ini bertujuan untuk mengulas masyarakat samin di era globalisasi yang segala aspek kehidupan mengalami kemajuan yang cukup pesat. Era globalisasi sangat rentan nilai-nilai, budaya dan norma mudah masuk dalam tatanan kehidupan masyarakat. Penelitian ini menggunakan metode penelitian kualitatif dengan pendekatan studi literatur. Sumber penelitian berasal dari sumber-sumber jurnal dan buku yang sesuai dengan pembahasan. Hasil penelitian dari pembahasan ini menunjukkan masyarakat samin menggunakan pola komunikasi Gethok Tular untuk menyampaikan informasi keresahan masyarakat samin kepada masyarakat lainnya.
\end{abstract}

Kata Kunci: Gerakan Sosial, Masyarakat, Samin, Globalisasi

\begin{abstract}
Today the progress of human civilization is progressing rapidly. Social change is no longer a foreign thing in the era of globalization. One of the indigenous peoples, namely the Samin community, has strong characteristics and the establishment to maintain its existence in social life. The Samin community has always carried out social movements against government policies that have damaged the lives of the Samin people. This article aims to review the Samin community in the era of globalization where all aspects of life are progressing quite rapidly. The era of globalization is very vulnerable to values, culture and norms that easily enter the order of people's lives. This study uses a literature study research method. Sources of research come from sources of journals and books that are in accordance with the discussion. The results of this study indicate that the Samin community uses the Gethok Tular communication pattern to convey information about the Samin community's unrest to other communities.
\end{abstract}

Keywords: Social Movement, Society, Samin, Globalization

Korespondensi:

Universitas Muhammadiyah PROF. DR. HAMKA

Jl. Tanah Merdeka, Kecamatan Ciracas, Jakarta

Timur

E-mail: pratamacahya344@gmail.com 


\section{PENDAHULUAN}

Indonesia merupakan negara yang kaya akan keberagaman dalam kehidupan masyarakatnya. Berbagai macam bahasa, ras, suku, agama dan budaya merupakan kekayaan yang harus dipelihara dan menjadi suatu kebanggaan bagi Indonesia. Solusi dari para pendahulu tokoh bangsa untuk merawat keberagaman yang dimiliki dibentuk suatu semboyan yang dikenal dengan Bhinneka Tunggal Ika yang memiliki definisi berbeda-beda tetapi tetap satu jua. Keberagaman ras, suku, agama dan budaya menciptakan masyarakat-masyarakat adat yang telah lama sudah ada keberadaannya di tiap wilayah Indonesia. Menurut Gina (Lestari 2015), sebagai negara yang memiliki keberagaman dan masyarakat yang heterogen, Indonesia memiliki kekayaan multi etnis, multi kultur dan multi agama yang kesemua hal tersebut menjadi penunjang untuk membangun negara yang kuat melalui multikultural nation state. Masyarakat adat memiliki karakteristik yang kuat karena hukum-hukum adat yang berasal dari leluhur selalu diwariskan kepada generasi masyarakat adat selanjutnya. Hal itu seringkali masyarakat adat selalu bergesekan dengan pemerintah dalam hal kebijakan yang dapat merugikan masyarakat adat dari segi sosial, budaya dan lingkungan alam.

Keberadaan masyarakat adat Indonesia telah diatur dalam Undang-Undang Dasar 1945 pasal $18 \mathrm{~b}$ ayat 2 menyatakan negara mengakui keberadaaan masyarakat adat dan hak-hak tradisionalnya selama hidupnya dan sesuai dengan perkembangan masyarakat Indoensia dan prinsip Negara Kesatuan Republik Indonesia (Sugiswati 2012). Dengan perlindungan masyarakat adat melalui undang-undang memberikan posisi secara konstitusi dalam kehidupannya. Keberadaan masyarakat adat sudah sejak dahulu dan dibuktikan dengan fakta sejarah yang menjelaskan eksistensi masyarakat adat dalam kehidupan sosial yang berkembang hingga saat ini. Maka dari itu sebelum terbentuknya negara Indonesia, masyarakat adat telah ada dan mengembangkan kehidupannya secara tradisional.

Jika menarik sejarah lampau, eksistensi masyarakat adat sejak dulu sudah ada sebelum negara Indonesia memproklamirkan kemerdekaan pada 17 Agustus 1945. Masyarakat adat hidup dengan hukum-hukum adat yang dibentuk oleh para pendiri maupun leluhurnya yang selalu dihormati. Hukum adat tersebut selalu berbeda dengan masyarakat adat lainnya. Hal ini dikarenakan kepercayaan maupun ideologi yang dianut setiap masyarakat adat berbeda satu 
sama lainnya. hukum adat dapat didefinisikan sebagai hukum yang keberadaanya berasal dari nilai-nilai, norma maupun budaya yang diyakini benar dan baik untuk diimplementasikan dalam kehidupan masyarakat adatnya. Adapun hukum adat yang berlaku di masyarakat adat yaitu hukum kekerabatan, perkawinan, waris, delik, tanah dan hukum lainnya (Syamsudin 2008).

Salah satu masyarakat adat yang keberadaanya hingga saat ini masih ada dalam kehidupan bernegara yaitu masyarakat samin. Masyarakat adat ini merupakan salah satu masyarakat adat yang saat ini masih kental dengan kebudayaan lokal yang telah mereka wariskan kepada generasi seterusnya. Masyarakat samin terletak di daerah-daerah Pulau Jawa diantaranya di daerah Pati, Rembang, Kudus, dan Blora (Feriandi, Malihah, and Maftuh 2020). Masyarakat samin sering bersikeras dengan pemerintah akibat kebijakan-kebijakan yang merugikan. Mayoritas perselisihan tersebut yaitu pembangunan-pembangunan yang dilakukan di wilayah pegunungan untuk mengeksploitasi sumber daya alam. Hal tersebut masyarakat samin melakukan perlawanan untuk tetap mempertahankan wilayah dan melestarikan lingkungan alam agar keseimbangan hidup tetap terjaga.

Masyarakat samin lahir dari kegelisahan dan perlawanan terhadap praktik kolonialisme di Indonesia saat terjadi penjajahan. Masyarakat samin lahir dari seorang tokoh yang bernama Samin Surosentiko yang disebut sebagai founding father. Ia lahir di Desa Kedhiren, Randublatung, Blora tahun 1859 (Hanifah 2019). Samin Surosentiko membentuk kelompok samin pada awalnya tidak pernah terpikirkan. Ia membentuk konsep pemikiran untuk melakukan perlawanan terhadap kolonialisme yang saat itu berkembang dan merugikan bangsa Indonesia. Budaya kolonialisme seperti perbudakan yang merajalela membuat masyarakat samin gelisah akan budaya yang tidak sesuai etika dan budaya lokal yang berkembang. Masyarakat samin sejak dahulu melakukan perlawanan-perlawanan kepada pemerintah. Pada awalnya masyarakat samin melakukan perlawanan terhadap kolonialisme Belanda dengan tidak membayar pajak. Seiring dengan waktu, masyarakat samin tetap berkembang di era globalisasi. Dalam kehidupan sosialnya, masyarakat samin menggunakan bahasa Jawa ngoko yang berbeda dengan bahasa Jawa pada umumnya. Bahasa Jawa ngoko ini terkesan kasar dalam pengucapannya kepada semua orang tanpa melihat derajat dan pangkat orang tersebut. Karena masyarakat samin berpandangan bahwa semua kedudukan memiliki derajat yang sama. 
Bentuk komunikasi masyarakat yang terkesan kasar merupakan suatu budaya yang dipercaya oleh leluhurnya dengan tujuan tertentu. Menurut Mulyana (Wibowo 2019), budaya merupakan suatu norma dan nilai yang dianggap sesuai dengan kehidupan kelompok tersebut. Sehingga setiap masyarakat adat memiliki kepercayaannya masing-masing yang berbeda dengan masyarakat adat lainnya. Pada umumnya masyarakat samin merupakan masyarakat yang selalu mengisolasi dari masyarakat non samin. Seluruh kegiatan hanya dilakukan di lingkungan kelompok masyarakat samin saja. Pola kehidupan seperti seiring dengan waktu terjadi perubahan ketika adanya rencana pembangunan pabrik semen yang ada di Sukolilo, Pati. Masyarakat samin mulai berani keluar dari kelompoknya dan berinteraksi dengan masyarakat lainnya.

Penelitian ini yang berjudul '’Pola Gerakan Sosial: Resistensi Masyarakat Samin di Era Globalisasi', menggunakan metode penelitian kualitatif deskriptif dan studi literatur yaitu dengan mencari referensi yang memiliki keterkaitan dengan permasalahan yang ada terkait dengan resistensi masyarakat samin di era globalisasi. Penelitian kualitatif merupakan penelitian yang digunakan dengan bertujuan untuk mengungkapkan fenomena yang terjadi supaya dapat memahami permasalahan yang sedang terjadi dengan cara mendeskripsikan baik dalam bentuk data, gambar, kata, dan bahasa (Yusuf 2014). Kemudian dalam teknik pengumpulan data, penulis menggunakan dengan cara melakukan studi literatur yang didapatkan melalui berbagai sumber seperti buku dan jurnal. Selanjutnya dalam pengolahan data, penulis menggunakan teknik analisis deskriptif. Teknik analisis deskriptif dilakukan dengan cara menguraikan fenomena maupun fakta yang ada, selanjutnya memberikan pemahaman dan penjelasan terkait permasalahan yang ada. Sebelum melakukan penelitian, peneliti telah menentukan topik penelitian, rumusan permasalahan untuk mempersiapkan pengumpulan data yang harus diperlukan.

\section{PEMBAHASAN}

\section{Historiografi Masyarakat Samin}

Masyarakat samin merupakan salah satu masyarakat adat yang tetap mempertahankan budaya dan ajaran para leluhurnya. Terbentuknya masyarakat samin tidak terlepas dari proses panjang sejarah masa lalu yang membentuk suatu kelompok tertentu. Masyarakat samin terbentuk oleh sosok seorang yang bernama Samin Surosentiko yang lahir pada tahun 1859 
bertempat di Desa Kedhiren, Randublatung, Kabupaten Blora (Aziz 2012). Masyarkat samin bermukim di daerah Jawa Tengah seperti Kabupaten Kudus, Pati, Rembang dan Blora. Samin Surosentiko bernama asli yaitu Raden Kohar kemudian memutuskan untuk mengubah menjadi Samin bertujuan agar nama tersebut menyimbolkan kerakyatan. Samin Surosentiko mulai menyebarkan ajarannya kepada masyarakat yang tinggal di desanya ketika berusia 31 tahun. Ajaran yang dilakukan oleh Samin mendapatkan respon yang baik dan diterima di hati masyarakat. Samin memiliki tempat di lingkungan masyarakatnya sehingga Samin menjadi seseorang yang teladan dan dinobatkan sebagai pemimpin masyarakat untuk melalukan gerakan.

Dengan ajaran yang disebarkan oleh Samin Surosentiko telah membentuk kelompok yang memiliki rasa dan nasib yang sama untuk diperjuangkan. Masyarakat samin memiliki istilah lain yaitu Sedulur Sikep. Masyarakat samin memiliki karakteristik sebagai kelompok yang lugu, sederhana dan tertutup dengan masyarakat lainnya sehingga masyarakat samin sulit untuk dipengaruhi oleh orang lain. Dalam ajaran yang dipegang teguh hingga saat ini yaitu hukum karma atau hukum sebab akibat. Masyarakat samin percaya bahwa apa yang diperbuat saat ini akan berdampak ke depannya sesuai dengan apa yang dilakukannya. Hukum tersebut diantaranya nandur pari, ngunduh pari (menanam padi dan memetik hasil panen padi); becik ketitik ala ketara (baik dan buruk akan berakibat sesuai dengan perbuatan) (Nurdin 2021).

Keberadaan masyarakat samin pada umumnya tinggal di wilayah agraria. Hidup berdampingan dengan alam yang masih asri. Menurut masyarakat samin alam yang disekitarnya harus dijaga dan dilestarikan karena alam merupakan warisan nenek moyangnya. Sehingga masyarakat samin menjaga sekuat mungkin agar alam dan lingkungan di sekitar tetap lestari dan diteruskan oleh generasi selanjutnya. Pandangan tersebut tidak terlepas dari falsafah hidupnya yaitu saminisme. Pola pikir masyarakat samin sangat sederhana. Tindakan ataupun pikiran yang dilakukan masyarakat samin selalu sesuai dengan keadaan. Masyarakat samin membagi dua konsep mengenai kehidupan di dunia antara lain wong (manusia) dan sandang pangan (penghidupan). Wong didefiniskan makhluk hidup salah satunya manusia yang ditujukan untuk mengelola kehidupan di bumi. Kemudian, sandang pangan merupakan hal-hal yang menjadi pelengkap atau sumber kehidupan manusia. Maka dari itu, dapat diartikan manusia dan lingkungan tidak dapat dipisahkan. Manusia seyogyanya tetap menjaga dan 
melestarikan lingkungan sebagai penyeimbang kehidupan makhluk hidup di bumi (Jumari et al. 2012).

\section{Gerakan Sosial Masyarakat Samin Era Kolonial}

Pada tahun 1890 praktik kolonialisme dan imperialisme melanda di Indonesia. Para penjajah memeras sumber daya manusia maupun alam yang dimiliki oleh bangsa Indonesia. Pada masa kolonialisme akhir abad 19 sampai awal abad 20 sering terjadi pemberontakan oleh masyarakat Jawa akibat kebijakan-kebijakan kolonial yang sangat merugikan masyarakat Jawa. Menurut Indah (Lestari 2013) Saminisme muncul dari berbagai reaksi pemerintahan kolonial saat itu, masyarakat samin memberontak tanpa fisik tetapi dengan sikap-sikap non fisik. Contohnya masyarakat samin dipaksa untuk melepaskan tanahnya tetapi masyarakat samin mengatakan bahwa tanah ini milik komunal dan sebagai perwujudan pemberian Tuhan Yang Maha Esa. Masyarakat adat tak luput dari kebijakan kolonial yang diterapkan di Jawa. Sektor pertanian dan hak kepemilikan sering terjadi permasalahan antara masyarakat Jawa dengan pihak penjajah. Dominasi bangsa barat yang kuat di Jawa menciptakan masyarakat membentuk kelompok dengan tujuan memprotes kebijakan. Adanya ajaran saminisme di kehidupan masyarakat Jawa merupakan hal yang positif dan menyadarkan masyarakat untuk mendapatkan hak-haknya. Ajaran saminisme ini mendapat respon dan diterima dengan baik oleh masyarakat sekitar. Kelompok yang dibentuk oleh Samin Surosentiko merupakan wadah untuk masyarakat mengaspirasikan kegelisahannya yang dirasakan selama kebijakan kolonialisme diterapkan di masyarakat Jawa. Samin Surosentiko menyebarkan ajarannya ke desa-desa dengan metode ceramah yang dilakukan di balai desa dan tanah lapang.

Masyarakat samin tersebar di beberapa wilayah seperti Jawa Tengah dan Jawa Timur. Pada umumnya, pekerjaan masyarakat samin berada di sektor agraria yaitu berladang, petani dan peternak. Pada tahun 1905, Samin Surosentiko berhasil memikat masyarakat untuk melakukan gerakas sosial dengan menolak semua kebijakan kolonialisme yang diberikan. Masyarakat samin menolak untuk membayar pajak, menolak menyumbang lumbung desa yang dikuasai oleh kolonial, menolak menggembala ternak bersama-sama (Aziz 2012).

Sejak melakukan gerakan kepada pemerintah kolonial, masyarakat samin memilki strategi yang berbeda dengan masyarakat pada umumnya yang melakukan aksi secara verbal. Masyarakat samin mempercayai bahwa komunikasi merupakan hal yang penting dalam 
melakukan gerakan. Berhasil atau tidaknya suatu gerakan mengacu kepada pengelolahan komunikasi yang dilalukan masyarakat. Menurut Burt (dalam Hapsari 2016) komunikasi berfungsi sebagai metode untuk menyebarluaskan orang-orang, kelompok dan organisasi sebagai bentuk penyaluran informasi, pesan maupun perilaku. Pola komunikasi masyarakat samin dilakukan non verbal atau sikap diam terhadap kebijakan pemerintah kolonial dengan menolak kebijakan-kebijakan yang ditujukan kepada masyarakat.

Masyarakat samin melawan dominasi bangsa barat atas hak tanah dengan kebijakan mewajibkan membayar pajak. Menurut Budi (Santoso 2016), aksi yang dilakukan oleh masyarakat samin merujuk kepada kepercayaan dan pemahaman bahwa tanah dan seisi alam merupakan warisan nenek moyangnya. Pemahaman masyarakat samin sebagai pewaris dari tanahnya untuk dijaga dan dilestarikan kepada generasi selanjutnya dan tidak mengharuskan membayar pajak oleh para penjajah yang sebagai pendatang di tanahnya.

\section{Pola Komunikasi Gerakan di Era Globalisasi: Samin Vs Semen}

Di era globalisasi memunculkan kemajuan zaman berupa teknologi, informasi dan komunikasi di berbagai sektor. Kemajuan lainnya juga berdampak kepada bidang lainnya seperti infrastruktur, ekonomi dan sosial. Fenomena kemajuan teknologi selalu berdampak dan beriringan dengan kehidupan manusia. Sehingga perubahan akibat dari globalisasi memiliki tantangan yang baru dan permasalahan yang selalu ada di kehidupan masyarakat. Di era Globalisasi yang mempengaruhi kehidupan manusia, masih ada masyarakat yang masih mempertahankan cara-cara tradisional. Masyarakat samin merupakan salah satu masyarakat yang memiliki rasa tradisional yang tinggi. Masyarakat samin di era globalisasi masih mempertahankan ajaran Samin Surosentiko yang menjadi founding father. Sehingga karakteristik masyarakat samin ingin membebaskan diri dari kehidupan modernisasi dan ikatan yang dikuasai oleh penguasa negara (Sri and Lestari 2017).

Kemajuan teknologi dan perubahan pola hidup masyarakat dunia berdampak kepada masyarakat samin. Masyarakat samin berusaha untuk mempertahankan adat istiadat di situasi modernitas yang tinggi. Salah satu kasus yang terjadi adalah pembangunan pabrik semen yang akan direncanakan di pegunungan kendeng, Pati, Jawa Tengah. Wilayah tersebut merupakan bagian dari wilayah masyarakat samin sehingga dengan adanya rencana pembangunan pabrik semen akan mengganggu dan menggusur kehidupan masyarakat samin yang telah lama tinggal 
di wilayah tersebut. kemudian masyarakat samin akan kehilangan profesinya yang mayoritas sebagai petani. Pandangan kehidupan masyarakat samin terkait peristiwa pembangunan pabrik semen ingin tetap mempertahankan mayoritas profesi petani masyarakat samin dan ingin menyelamatkan dan tetap melestarikan pegunungan yang sejak dahulu sudah menjadi sumber kehidupan masyarakat samin (Darmastuti et al. 2016).

Masyarakat samin memperhatikan lingkungan yang merupakan salah satu warisan nenek moyangnya. Kepercayaan dan pemahaman masyarakat samin mengenai lingkungan sebagai sandang pangan didefinisikan sebagai sumber penghidupan untuk menunjang kehidupan manusia sehari-hari. Dengan beberapa alasan tersebut, masyarakat mengecam dan menolak pembangunan pabrik semen. Pola komunikasi masyarakat samin terdapat perubahan. Sebelumnya penyebaran informasi dilakukan oleh pemimpin ataupun sesepuh untuk disampaikan kepada masyarakat lainnya atau masyaarakat non samin. Sebelumnya masyarakat samin mengisolasi diri dari masyarakat luar kemudian masyarakat samin berkontribusi untuk melakukan aksi bersama-sama masyarakat luar (Darmastuti 2016). Dengan adanya pembangunan pabrik semen di Pegunungan Kendeng, Pati, Jawa Tengah semua masyarakat samin berhak untuk menyebarluaskan keresahan terhadap pembangunan pabrik semen kepada masyarakat non samin untuk melakukan gerakan sosial.

Dalam melakukan gerakan aksi tolak pembangunan pabrik semen, masyarakat samin menggunakan pola komunikasi yang disebut dengan gethok tular (pesan berantai) untuk menyebarluaskan kepada masyarakat non samin agar menolak pembangunan pabrik semen dan tetap mengajak melestarikan lingkungan agar bisa dinikmati oleh generasi selanjutnya. Pola komunikasi yang dilakukan oleh masyarakat tidak terlepas dari pengaruh budaya yang dipercayainya. Menurut Nakayama (Darmastuti et al. 2016) nilai-nilai kebubudayaan yang dipahami dan dipercaya oleh masyarakat tertentu akan mempengaruhi fenomena pola komunikasi yang dilakukan oleh kelompok masyarakat tertentu.

Gethok tular merupakan pola komunikasi yang sangat efektif untuk menyampaikan informasi kepada masyarakat samin lainnya dan masyarakat non samin. Berdasarkan budaya masyarakat samin yang mengacu kepada budaya Jawa mengajarkan untuk hidup selaras dan damai yang diimplementasikan dengan hidup rukun, asri dan hormat. Gerakan yang dilakukan dengan prinsip tanpa ada kekerasan. Masyarakat samin tetapi berpegang teguh kepada prinsip sopan santun. Menurut Clifford Geertz yang meneliti masyarakat Jawa, hidup rukun 
merupakan salah satu metode untuk hidup bersama saling damai dan membantu sesama untuk kemajuan di zaman baru (Cliffoord Geertz 2013).

\section{KESIMPULAN}

Berdasarkan hasil pembahasan dapat disimpulkan bahwa era globalisasi telah mengubah tatanan kehidupan masyarakat dunia. Berbagai sendi-sendi kehidupan masyarakat telah terjadi perubahan sosial yang mempengaruhi cara ataupun pandangan hidup kelompok tersebut. Derasnya globalisasi, terdapat masyarakat adat yang masih mempertahankan adat istiadat secara turun-menurun. Masyarakat samin berada di wilayah Jawa Tengah dan Jawa Timur. Masyarakat samin berpegang teguh kepada ajaran Samin Surosentiko yang membentuk kelompok untuk melakukan gerakan menolak kebijakan kolonialisme. Kemudian ajaran tersebut hingga saat ini masih dipertahankan.

Adanya pembangunan pabrik semen di Pati, Jawa Tengah membuat resah masyarakat samin. Karena wilayah yang akan dibangun pabrik semen merupakan sumber penghidupan bagi masyarakat sekitarnya. Dan masyarakat samin berpegang teguh bahwa lingkungan merupakan warisan nenek moyangnya yang harus dipertahankan untuk generasi selanjutnya. Masyarakat samin melakukan gerakan dengan pola komunikasi yang disampaikan secara berantai. Dari pembahasan tersebut dapat ditemukan pola komunikasi yang dilakukan oleh masyarakat samin untuk melakukan aksi tolak pembangunan pabrik semen yaitu pola komunikasi gethok tular. Gethok tular merupakan strategi yang digunakan oleh masyarakat samin untuk menyampaikan keresahan pembangunan pabrik semen kepada masyarakat samin maupun non samin agar tetap melestarikan lingkungan untuk diwariskan ke generasi selanjutnya. 


\section{DAFTAR PUSTAKA}

Aziz, Munawir. 2012. "IDENTITAS KAUM SAMIN PASCA KOLONIA PERGULATAN NEGARA, AGAMA, DAN ADAT DALAM PRO-KONTRA PEMBANGUNAN PABRIK SEMEN DI SUKOLILO, PATI, JAWA TENGAH.” Kawistara 2(3):225-328.

Cliffoord Geertz. 2013. Agama Jawa: Abangan, Santri, Priyayi Dalam Kebudayaan Jawa. Depok: Komunitas Bambu. Depok: Komunitas Bambu.

Darmastuti, Rini. 2016. Pola Komunikasi Dan Konstruksi Identitas Masyarakat Samin (Studi Etnografi Komunikasi Dalam Gerakan Sosial Di Sukolilo, Pati, Jawa Tengah). Bandung: Universitas Padjajaran.

Darmastuti, Rini, Atwar Bajari, Haryo S. Martodirdjo, and Eni Maryani. 2016. "Gethok Tular, Pola Komunikasi Gerakan Sosial Berbasis Kearifan Lokal Masyarakat Samin Di Sukolilo.” Jurnal ASPIKOM 3(1):104. doi: 10.24329/aspikom.v3i1.103.

Feriandi, Yoga Ardian, Elly Malihah, and Bunyamin Maftuh. 2020. "Resistensi Kelompok Samin Terhadap Modernitas Revolusi Industri 4.0." Jurnal Ilmiah Mimbar Demokrasi 20(1):97-105. doi: 10.21009/jimd.v20i1.15662.

Hanifah, Umi. 2019. "TRANSFORMASI SOSIAL MASYARAKAT SAMIN Di BOJONEGORO (Analisis Perubahan Sosial Dalam Pembagian Kerja Dan Solidaritas Sosial Emile Durkheim).” Jurnal Sosiologi Agama 13(1):41.

Hapsari, Dwi Retno. 2016. "Peran Jaringan Komunikasi Dalam Gerakan Sosial Untuk Pelestarian Lingkungan Hidup." Jurnal Komunikasi Ikatan Sarjana Komunikasi Indonesia 1(1):25. doi: 10.25008/jkiski.v1i1.33.

Jumari, Jumari, Dede Setiadi, Y. Purwanto, and Edi Guhardja. 2012. "Etnoekologi Masyarakat Samin Kudus Jawa Tengah." Bioma: Berkala Ilmiah Biologi 14(1):7. doi: 10.14710/bioma.14.1.7-16.

Lestari, Gina. 2015. "Bhinnekha Tunggal Ika: Khasanah Multikultural Indonesia Di Tengah Kehidupan Sara.” Jurnal Pendidikan Pancasila Dan Kewarganegaraan 28(1):31-37.

Lestari, Indah Puji. 2013. "Interaksi Sosial Komunitas Samin Dengan Masyarakat Sekitar." KOMUNITAS: International Journal of Indonesian Society and Culture 5(1):74-86.

Nurdin, Nazar. 2021. "TRADISI PERLAWANAN KULTURAL MASYARAKAT SAMIN." Jurnal Sosiologi Agama: Jurnal Ilmiah Sosiologi Agama Dan Perubahan Sosial 15(1).

Santoso, Budi. 2016. Hanggo Puspo Aji: Ajaran Dan Sejarah Pergerakan Samin Surosentiko. Semarang: ELSA Press.

Sri, Indah, and Puji Lestari. 2017. "MASYARAKAT SAMIN DITINJAU DARI SEJARAH DAN NILAI-NILAI PENDIDIKAN KARAKTER.” Jurnal Istoria 13(1). 
Sugiswati, Besse. 2012. "Perlindungan Hukum Terhadap Eksistensi Masyarakat Adat Di Indonesia.” Perspektif XVII(1).

Syamsudin, Syamsudin. 2008. "Beban Masyarakat Adat Menghadapi Hukum Negara.” Jurnal Hukum Ius Quia Iustum 15(3):338-51.

Wibowo, Ari. 2019. "Pola Komunikasi Masyarakat Adat.” Khazanah Sosial 1(1):15-31.

Yusuf. 2014. Metode Penelitian: Kuantitatif, Kualitatif, Dan Penelitian Gabungan. Jakarta: PT. Fajar Interpratama Mandiri. 